Article

\title{
The Terms Foresters and Planners in the United States Use to Infer Sustainability in Forest Management Plans: A Survey Analysis
}

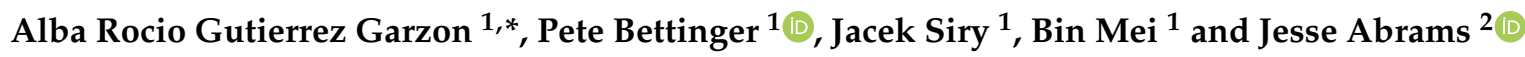 \\ 1 Warnell School of Forestry and Natural Resources, University of Georgia, Athens, GA 30602, USA; \\ pbettinger@warnell.uga.edu (P.B.); jsiry@uga.edu (J.S.); bmei@uga.edu (B.M.) \\ 2 Warnell School of Forestry and Natural Resources and Savannah River Ecology Laboratory, Athens, \\ GA 30602, USA; jesse.abrams@uga.edu \\ * Correspondence: garzon@uga.edu
}

Received: 4 December 2019; Accepted: 15 December 2019; Published: 18 December 2019

\begin{abstract}
Sustainable forest management is important for advancing sustainable societal development. Effective communication plays a major role in how goals and objectives are achieved. This study aims to assess how sustainability is considered by people who develop forest management plans (or forest plans in short). We employed the snowball sample technique to locate the study's respondents. In addition, an open-ended questionnaire and a mix method data collection (phone and email) and analysis (qualitative and quantitative) were found to be adequate methods to survey forest planners who have been involved in the development, implementation, evaluation, and/or revision of forest plans in the United States. Our approach helped us to understand their perceptions of and means of incorporating sustainability concerns in forest plans. A total of 55 surveys were completed by forest planners physically located in 26 of the 50 states in the country. Results suggested that planners generally placed environmental sustainability concerns over social and economic sustainability concerns. A variety of key terms were central to forest planners' attempts to communicate sustainability, from which most were associated with philosophical and temporal principles that would then be associated with concrete actions and the human dimension. Nevertheless, respondents also acknowledged difficulties and misunderstandings in describing how forest sustainability should be demonstrated within a forest plan. Topics such as restoration, carbon sequestration, and resilience were infrequently associated with sustainability and sustainable forest management. Finally, we found that the respondents were divided on whether the language used in forest plans to demonstrate sustainability could be improved.
\end{abstract}

Keywords: forest management; forest planning; open-ended questionnaire; survey; snowball sampling

\section{Introduction}

Humans have used forest resources for thousands of years, and the sustainability of forest resources has been discussed and debated for at least the last three hundred [1]. The concept of the sustainability of forests was likely first introduced as a principle of German forestry in the 18th century by Hans Carl von Carlowitz (1645-1714) in his book Silvicultura Oeconomica [2,3]. At that time in human history and in the present, the concept of sustainability has signified managing a forest for ecological, economic, and social considerations [2]. In recent decades, global and national natural resource management organizations, including the International Union of Forest Research Organizations, the Food and Agriculture Organization of the United Nations, the United States Forest 
Service, and the Society of American Foresters, among others, have developed definitions for forest sustainability. When compared (Figure 1), these tend to use largely consistent language regarding the human use of forest resources at a level that provides sufficient ecosystem services for current and future societal needs.

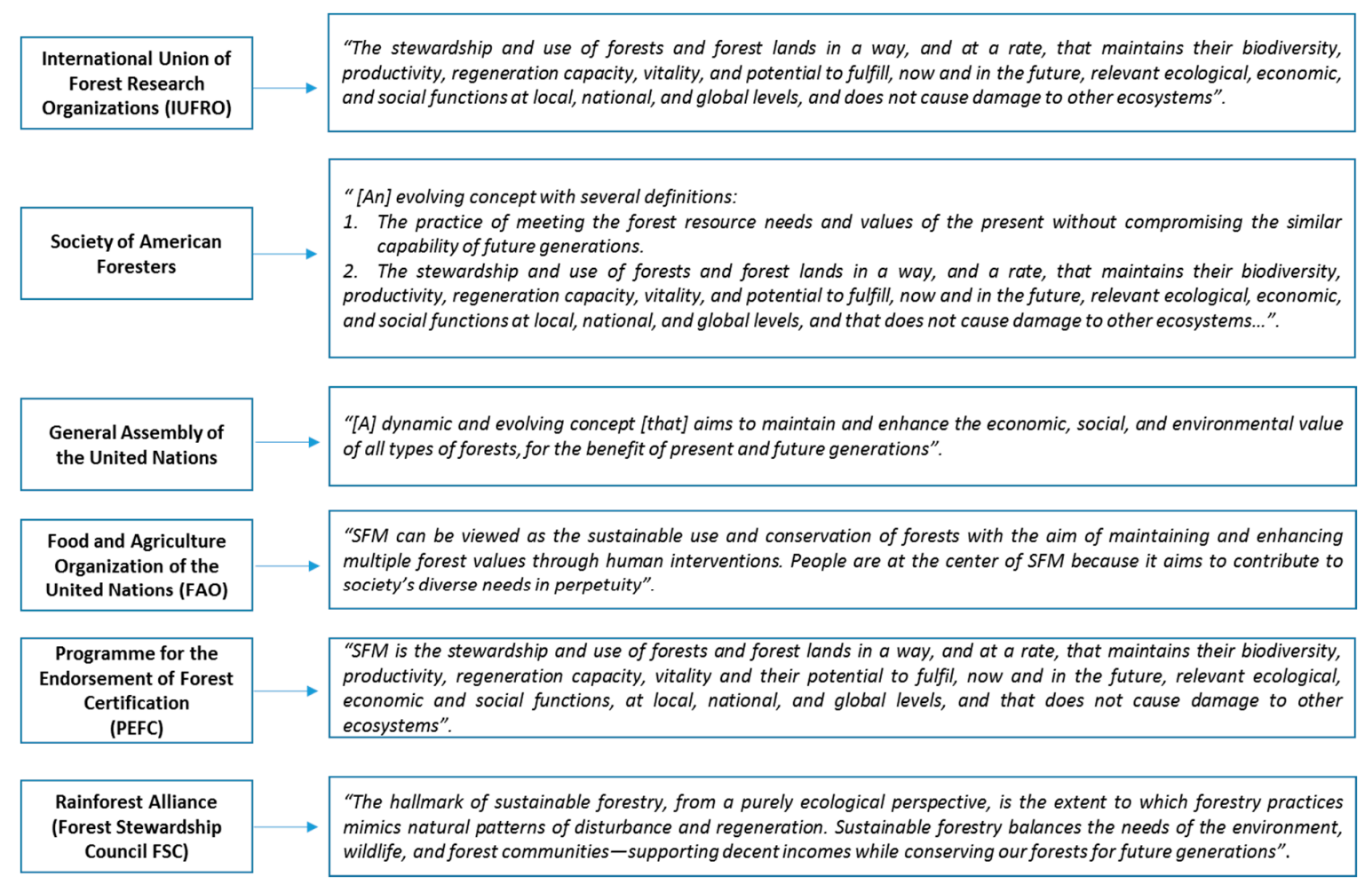

Figure 1. Definitions of sustainable forest management (SFM) [4-8].

Sustainability emerged in the late 20th century as a critical concept of policy debates [9] and today, the general concept of sustainability permeates many areas of science, management, and governance [10]. With respect to the general management of a business, sustainability can be viewed as a megatrend [11], often expressed in terms of the ability of an organization to endure and to produce goods and services for a long period of time [12]. In general, an organization that acts sustainably provides or uses resources related to human welfare that will be maintained or improved over time [11]. Some have even suggested that the concepts of peace and conflict should be included in deliberations on sustainability, as they could disrupt management direction [10]. With respect to forest businesses and forest management organizations, sustainability is an ethical principle that addresses the long-term ecological, economic, and social outcomes of management [4]. Social foundations, economic resources, institutional characteristics, and environmental couplings are major areas of discussion that assist in determining whether a forest system is sustainable [13,14]. Definitions of sustainability, and assessments regarding whether a system is sustainable, can create controversy when shared metrics and evidentiary standards are lacking [15]. In general, the moral principle of intergenerational equity often guides actions regarding the sustainability of systems [9].

Much of the contemporary discourse on forest sustainability has its roots in the 1987 Brundtland Commission, whose report Our Common Future highlighted the interconnections between and within environmental, social, and economic facets [16]. Outcomes from the United Nations Conference on Environment and Development in Rio de Janeiro (the Earth Summit) in 1992 helped inspire a common understanding of sustainable forest management (SFM) as a system of management that seeks from a forest the sustained yields of several different products and services without diminishing future forest capacity [17-20], without causing damage to other ecosystems, and while maintaining vitality, 
regenerative capacity, biodiversity, and productivity [4]. SFM has been put forward as a way to achieve sustainable development within society by addressing the needs of the present without affecting the needs of the future [21,22]. The International Tropical Timber Organization was perhaps the first to develop criteria to evaluate the effectiveness of SFM [17]. Criteria and indicators for monitoring the effectiveness of SFM have since been incorporated into various voluntary forest certification programs [23], such as the Forest Stewardship Council (FSC), the Sustainable Forest Initiative (SFI), and the American Tree Farm System (ATFS). The last two started in the United States, while the FSC was formed by an international consortium of actors in the wake of the 1992 Earth Summit in Rio de Janeiro. Although these programs all utilize market-based instruments as a means of promoting and identifying sustainably managed forests, they differ somewhat in their scope and focus. These efforts have continued to adapt in response to evolving understandings of forest sustainability, including those advanced by the Montreal Process in 1995 and other subsequent commissions [18,20].

Managing forests for the greater societal good is a lofty and inspiring goal that can appeal to land managers and various social actors. Three of the most well-known philosophical approaches to forest sustainability are (1) sustained-yield forestry, (2) multiple-use management, and (3) ecosystem management [24-26]. The basis of the sustained yield approach to sustainability entails managing a forest resource in such a manner that the intensity, location, and timing of planned activities produce a predictable and relatively constant amount of merchantable forest products over time. Multiple-use management, on the other hand, goes beyond the resource-specific consideration and, instead, aims to manage multiple resources (e.g., forest, water, wildlife) in a joined manner to produce a combination of services from the ecosystem. The crux of the ecosystem-oriented approach to sustainability involves managing a forest resource in such a manner that the intensity, location, and timing of planned activities do not affect biodiversity, ecological function, social goals, and future forest production [27]. Each of these three philosophies can act as valid approaches to forest sustainability, if supported by projected outcomes that relate to the goals and objectives of the landowner and that illustrate how resources are maintained or improved over the long term.

The manner in which forest sustainability is demonstrated is an important issue today. Agriculture, forestry, and other land uses are estimated to account for about $23 \%$ of the total net anthropogenic emissions of greenhouse gases; sustainable forest management has been suggested as a way to lower these emissions [28]. With this increasing concern of greenhouse gases in the Earth's atmosphere, the removal of carbon dioxide through the management of forests has become an important issue in forest planning [29]. In fact, for over a decade forest carbon planning opportunities and carbon footprints have been considered in some native American [30], public [31,32], private [33], and non-governmental organization [34] forest plans. Issues such as balancing carbon removal with carbon sequestration can be integrated into a forest management plan [35] and the blending of carbon sequestration goals into forest plans with efforts to adapt forest management to address the changing climate, has been acknowledged and demonstrated [29,36,37]. As economic incentives, documented carbon offsets offer a revenue opportunity for forest landowners [38]. Programs such as the California Air Resources Board carbon market and the Regional Greenhouse Gas Initiative (northeastern US) offer market-based opportunities for forest landowners to earn revenue through improved forest management projects that demonstrate forest carbon offset potential [39]. These opportunities may prompt forest landowners to develop forest management plans that directly address carbon sequestration and climate change. Lands that are also covered by conservation easements or other agreements [40] can be associated with forest management plans that help protect and address a myriad of ecosystem services and public benefits, such as carbon sequestration [41]. As an example, the US Federal Legacy Program is one program that has helped conserve over 2.6 million acres through conservation easements and direct land purchases. The Forest Climate Action Team [42] in California has also encouraged collaborative planning efforts among landowners to enact forest management planning in a manner that addresses forest health and forest resilience. As a result of these advances and opportunities, forest landowners 
and land managers can build trust with society through an approach to forest management that demonstrates the effects of management on forest sustainability.

However, demonstrating how forests sustainably supply goods and services, maintain ecological functions, and contribute to economic and social well-being can be challenging [17]. Depending on the circumstances (ownership, geography, markets, etc.), the implementation of sustainable practices may not be easy [43]. As with any complex endeavor, there may be limitations on the data, technology, personnel, and organizational commitment necessary to achieve success [44]. Often, a written forest plan is used to demonstrate that forests are able to sustain various resources and services in the long term [45]. A forest plan is a general framework that describes proposed activities that best address the management objectives of a landowner. Broadly, a forest plan includes information on the management goals and objectives of the landowner, inventory and description of the forest's current conditions and resources to be managed, the formulation of management alternatives (which ideally would be the results of assessing environmental, social, and economic outcomes), and a management recommendation that describes the plan of action [24]. Robust ways to signal a commitment to sustainability within forest plans would involve explicit estimates, measures, and monitored outcomes of a management process that indicate that the management path forward (through time) can sustain important social, economic, and environmental outcomes. While the simple existence of a forest plan might suggest to some that the associated forest direction is sustainable, several studies have suggested that there may be a lack of empirical evidence concerning outcomes of sustainability within forest plans (e.g., [20,46,47]). Unfortunately, in some cases, evidence of the sustainability of a forest system within a forest plan can consist largely of vague rhetorical statements [48].

To further investigate these matters, we surveyed forest planners (the subject of this research) though an open-ended questionnaire, to inform an extensive content analysis of plans (the subject of future research) regarding the manner in which sustainability is communicated and demonstrated in forest plans. This manuscript presents the results of data-gathering and coding exercise that focused on what terms forest planners frequently associate with sustainability and SFM. The survey was intended to answer the following two questions:

1. What are the most frequent terms forest planners associate with sustainability in forest plans?

2. To what extent does the conceptualization of sustainability in forest plans include environmental, social, and economic considerations?

Language has a tremendous influence in the way we communicate concepts to others and perhaps, more importantly, the way in which individuals predispose their minds to learn and act. Our interest in understanding the use of terms associated with sustainability and SFM arose because of the overuse of these words both in the media and organizations seeking recognition and social acceptance. This research was also crafted in response to statements such as those from [49] who discusses the loss of the environment's intrinsic values (e.g., aesthetic, cultural, and spiritual values) when these are collapsed into "weak" economic values and claims such as those from [50] who criticize the sustainability definition as given by the Brundtland Commission. Their critique is that the widely used definition does not offer any strategies to "operationalize" the concept, thus increasing its subjectivity and leading to variable interpretations (e.g., corporate sustainability initiatives that are sometimes criticized as "greenwashing"). In our study, we recognize that both the framing and the explicit demonstrations of forest sustainability are context-dependent and determined by additional aspects such as culture, economic interests, and institutional capacity, among others. Nevertheless, in light of the substantial effort by scholars and practitioners to define and operationalize sustainability in forest management since the publication of the Brundtland Report, our hypotheses are that (1) forest planners in the United States are guided by broadly similar concepts of forest sustainability and (2) that environmental, social, and economic dimensions are all addressed within forest plans. These hypotheses reflect the convergence of sustainability conceptualizations within the forestry sector (Figure 1) and across various fields of practice more broadly. They are influenced by prior work that suggests tradition and 
habit have an important role in how sustainability is operationalized, and by the growing demand to integrate multiple dimensions of sustainability into forest management [51].

\section{Materials and Methods}

To understand the keywords, phrases, and concepts related to sustainability as held by forest planners in the United States, we used an open-ended questionnaire. Open-ended questions are often used to explore topics in depth, to understand processes, and to identify potential causes of a particular event [52]. On the basis of 13 questions (Figure 2), the survey was designed to obtain from respondents their definition of sustainability and SFM and the keywords that they associate with these concepts. In addition, the survey included questions designed to elicit responses about the manner in which sustainability is demonstrated in forest plans. This format of the survey produced information in the form of lists, short answers, and on occasion, lengthy comments. Because the structure of the survey provided rich content, iterative analysis and coding of the survey answers were needed to validate insights, themes, and ideas, as detailed below.

We considered the population of interest (and source of data for our study) to be forest planners who were working in the United States, regardless of any other sub-classification. People responsible for the coordination of maps, inventories, and schedules of proposed activities are referred to as forest planners [4]. The main criterion to select our respondents was that they needed to have participated or been involved in the design, implementation, revision, evaluation, and/or monitoring of forest plans. The population consisted of forest planners employed by both public and private land management organizations. Forest planners working for public organizations were employed by national forests, state forests, cities, and public educational institutions. Consultants to non-industrial private landowners, industry-employed forest planners, and people working for tribal organizations and private educational institutions were considered forest planners working for private organizations.

The size of the total population of interest was not clearly evident, since there is no sampling frame for forest planners. We used convenience sampling to determine the initial seeds for a snowball sampling process [53] that would allow us to locate additional potential respondents for our survey [54,55], as it was not possible to conduct a random sample of a known population. We began our sample with an initial set of planners that we knew were actively engaged in the development of forest plans. These people included current forest planners employed by several national or state forests, forestry consultants, and other people in the field of forestry who met the criterion to participate in the survey.

The initial sample was shaped to be as diverse as possible and representative of individuals involved in the development of forest plans for private and public lands. Sample respondents beyond the initial sample were located through snowball sampling, a widely used technique in qualitative sociological research to locate potential sample respondents to surveys [54,56]. Snowball sampling has also been used to locate scientific literature pertaining to specific research agendas $[57,58]$ and is often characterized as chain referral sampling [59] or respondent-driven sampling [60]; these terms are often used interchangeably even though the last two might in practice be used differently. Other studies have suggested this process as a way to overcome data sampling problems associated with members of special populations [61,62]. For example, the sampling process has been applied to virtual networks facilitated by the Internet to engage hard-to-reach populations [62]. However, some have expressed concern about the diversity (demographic, geographic, and occupational) of the sample developed along the referral chain and about the variance of estimates derived from these types of samples [60].

As with other similar surveys applied to other fields (e.g., [56]), the objective of the snowball sample was to collect unique knowledge among those involved in the development of forest plans. With respect to chain referral, the study respondents were asked to provide the contact information of other potential respondents who shared similar experiential characteristics (had developed forest plans). The survey administrator controlled the initiation, progress, and termination of the sampling process, which included locating potential respondents, engaging them, and monitoring referral 
chains [59]. This sampling process was advantageous for locating study respondents who could adequately address a specific topic such as the development of forest plans.

Questionnaire

Name of respondent:

Organization:

Role:

Contact information:

1. Have you participated in the design implementation revision of one or more forest management plans? If so, please provide dates.

2. How would you define or describe sustainability?

3. How would you define or describe sustainable forest management?

4. What are the main regulations a planner/forester has to comply with when writing and implementing sustainable forest management?

5. How familiar are you with any sustainable forest management principles? Not at all familiar Please mention them.

6. What do you think is fundamental to achieve sustainable forest management?

7. Please provide a list of terms that you associate with sustainability. List them in order of importance

8. Please provide a list of term that you associate with sustainable forest management. List them in order of importance.

9. In what way is forest sustainability demonstrated in the Forest Manag ement Plan (FMP) you helped to develop?

10. Could commitment to "sustainability" be demonstrated more through the language employed in FMP? If so, how?

11. Could you please suggest one (or more) professional (s) who you think might be a potential respondent to this interview? Does not have to be part of your current organization.

Name:

Email/phone number:

12. Do you have any additional comments?

13. May I contact you ag ain if I have any further questions?

Figure 2. Survey questionnaire.

The decision to terminate a snowball survey may be based on a high level of repetition of the data collected, the representativeness of the sample, or other practical considerations [59]. Therefore, the sampling process continues until a time when the researcher decides that the sample is sufficiently representative of the population, when the respondents begin to repeat names of potential additional respondents, or when the sample has become saturated (no new significant information is being collected) [54,55]. Our snowball sampling process was terminated at a time when (a) it appeared that people being contacted did not reply anymore, (b) study respondents stopped suggesting new potential candidates for the survey, and (c) no new information seemed to be collected with each additional set of responses. Our sample size (55 respondents), small as it may seem, was consistent with 
similar surveys conducted in natural resource management and other fields (e.g., [56]). For example, one survey of natural resource management professionals involved ascertaining opinions from 57 study respondents on challenges facing landscape management [63].

The main mode of initial communication with potential respondents of our survey was through an email invitation, as we considered it particularly efficient for data collection [64]; however, we made some initial contacts through direct telephone calls. All potential respondents received an "invitation-to-participate" email that contained information related to the aim of the study, the sampling process, and the expected outcomes. This information was accompanied by a consent letter and the open-ended questionnaire form. Within the body of the email, respondents were encouraged to either complete the survey questionnaire and email it back to the administrators of the survey or to schedule a time to respond to the survey by phone. Thus, to obtain survey responses, we used a mixed-mode, or Type 3 approach (use of two different modes to collect responses from different people) according to [65]. Mixed mode approaches are often employed to improve coverage of a target population, to reduce costs, to improve response rates, to ease the efforts of the responder, and to potentially reduce nonresponse error. The Type 3 approach we employed using both a written questionnaire and telephone interview processes focused on improving coverage of the population, as we were concerned about a low response rate and proper coverage of the target population. By offering respondents a mode that they prefer can improve survey response rates, as respondents may be reluctant to participate via one mode or another [65].

For those respondents who simply received the initial email and delivered their responses back to us through email (43 completed surveys), we neither tracked nor asked them to note the time required to complete the survey questionnaire. The average time spent with telephone-administered respondents (12 completed surveys) was $20 \mathrm{~min}$. Surveys completed by telephone were audio-recorded with the respondent's consent, and a complete transcription (verbatim) was carried out by the first author of this research not more than two days after the survey was conducted. Recordings were deleted after the transcription to protect the privacy and anonymity of respondents. For participation in our survey, we promised respondents a high level of data protection and confidentiality. Once written responses were received, basic demographic information was attributed to each set and any indication of respondent's identities were removed. The same held for transcribing telephone interviews into written responses. During a telephone interview, a respondent may share information and experiences that may jeopardize their employment, so while the audio record of responses may be a valuable resource, it is suggested that recorded data should be destroyed after transcription to alleviate concerns about anonymity and confidentiality [66]. Concerns about voice recognition prompted our decision to delete these calls once the information had been properly transcribed so that respondents can never be traced or identified by other people who may access these files. We ensured respondents of these protocols in an effort to increase their willingness to participate in the survey. This action also provides a sense of confidentiality to the respondent should they have made a statement revealing more than they should, subsequently qualified by comments such as "please don't use this" [67]. Retracting comments during the survey is required to comply with the desires of the respondent, but the oral record might still remain in the recorded version. As suggested by [68], until there exists empirical data on potential effects of survey participation, a very cautious approach to anonymity and confidentiality should be pursued, disassociating any personal characteristics (in this case, voices) from the data that has been received.

Potential limitations of this type of sampling process include variations in verbal skills, language skills, literacy levels, and visual impairments, among others [69]. The mixed mode survey (email and phone) was not considered an obstacle to deliver the questions nor to retrieve the responses. We chose these processes over face-to-face interviews so that we could access a geographically diverse set of respondents [70]. Finally, because the study involved human subjects, we obtained University of Georgia Institutional Review Board authorization prior to initiating any contact with potential respondents. 
Once the surveys were compiled, we analyzed the data in order to discover potential patterns, themes, and categories. Through an iterative process, we coded the responses and divided them into manageable units of analysis that were then categorized or put under "headings" of groups of themes. These steps are comparable to some of the components (unitizing, coding, reducing, inferring, and narrating) needed to move from textual responses to results, as described by [71]. Specifically, we performed a quantitative analysis to describe demographic patterns and to present the list of the most frequently used words to define sustainability and SFM according to our study respondents. We used ATLAS.ti qualitative text analysis software for the frequency query on responses to questions 2 and 3. Four terms (sustainability, SFM, forest, and management) were excluded from the analysis of frequency, as were their corresponding stemmed words. In addition, the qualitative analysis (used for questions 2-6 and 9-10) involved the following five stages. First, we placed the answers to each question from each respondent into a text file (using Microsoft Word). Second, we read them and made notes of possible themes within the answers so that we could get immersed into the respondent's world [72] and be able to develop a sense for potential relations among the answers obtained [73]. Third, we read the answers again and described all aspects of the content, ignoring issues unrelated to our main topic (sustainability and SFM). This step is also known as open coding [72,73] and allowed us to freely generate categories or groups of related content. The fourth stage involved a review, reorganization, and reduction of higher-order categories [72]. Finally, with the set of categories in mind, survey responses were read one more time allowing us to generate the results related to forest principles or main considerations for forest sustainability and the findings on demonstrations of forest sustainability within forest plans according to our study respondents.

Mixed quantitative/qualitative approaches such as these are often used in survey research (e.g., $[74,75])$. The two forms of research methods are not mutually exclusive, they are often used in concert to provide measurements and understand magnitudes and indicators (quantitative) and to delve deeper and provide insight through open-ended questions (qualitative). In our case, while we used open-ended questions to elicit opinions, the analysis of word frequencies (content analysis of responses) helped us support our recommendation of terms for a broader content analysis of forest plans. The methods can be integrated in a variety of ways, and both have advantages (quantitative provides facts, qualitative provides insights) and disadvantages (quantitative is limited, qualitative is more difficult to analyze).

\section{Results}

The survey was conducted between January and March 2019. The respondents were physically located in 26 of the 50 states in the country (Figure 3), even though they may have developed forest plans for properties in states other than their home state. The greatest number of responses was obtained from forest planners employed by public organizations, who represented $67.3 \%$ of the respondents (Table 1). This set of respondents consisted of a similar number (15) from both federal and state organizations along with a few from cities and public educational institutions.

From forest planners employed by private organizations accounted for $32.7 \%$ of the responses. Most of these respondents (10) were consultants, but forest planners working for the forest industry, timberland investment and management organizations, and other private organizations were represented in this sample. While the responses appear to favor publicly employed forest planners, we are confident in that the sample represents well the amount of land area in each ownership group that is represented by a forest plan. According to reference [76], 35\% of the 333 million ha of United States forest and woodland is publicly owned, $16 \%$ is owned by corporate entities (timber companies, real estate investment trusts, and timberland investment and management organizations), and $43 \%$ of forest and woodland is owned by families, trusts, estates, and family partnerships. We believe that nearly all public lands and corporate entities should have an active forest plan. We also assume that $12.9 \%$ of private landowners have a plan, that $38.5 \%$ of these were written by consultants or industry-employed forest planners, and that $35.6 \%$ of these were written by forest planners from public organizations [77]. 
Therefore, approximately 183.5 million ha of forest and woodland has a forest plan written by forest planners employed by either a public or private organization.

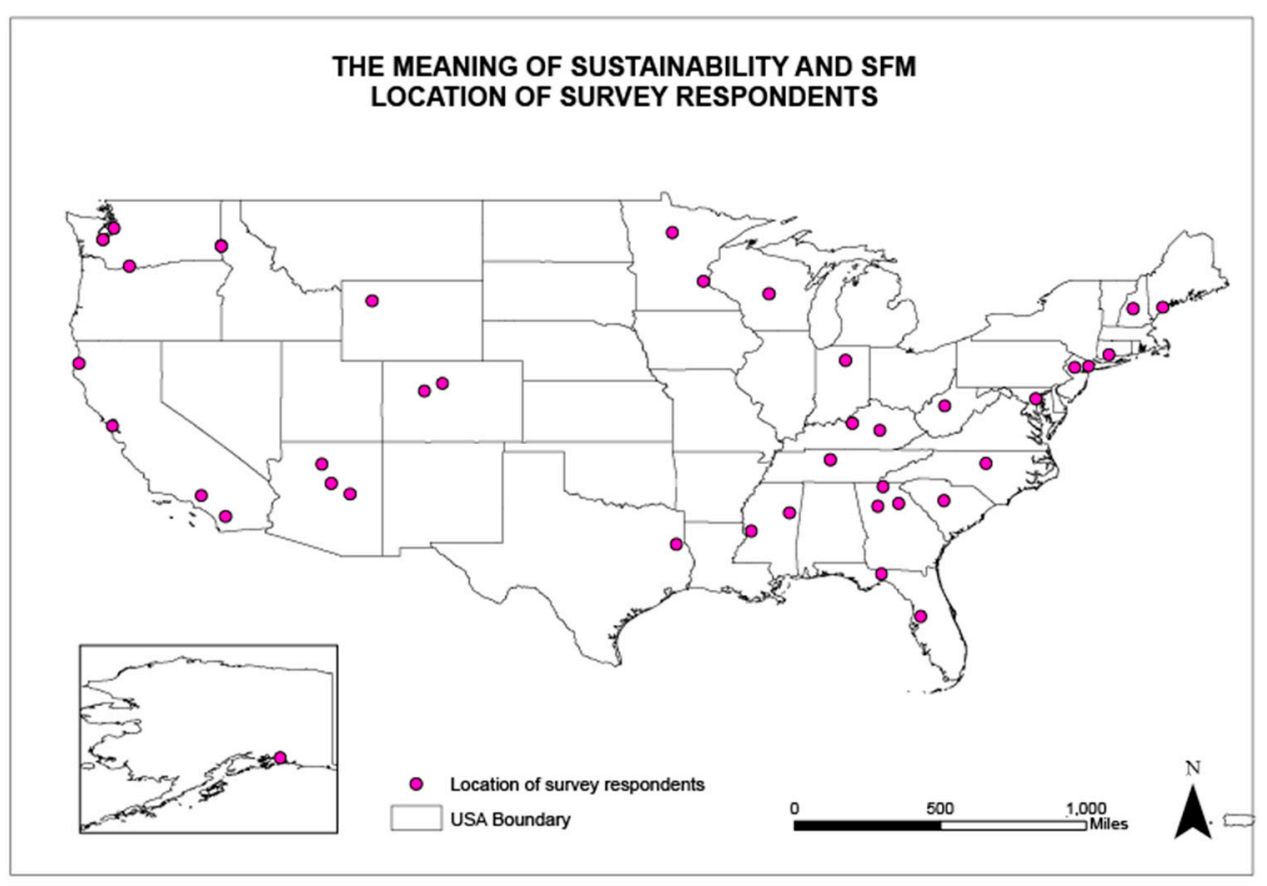

Figure 3. Point location of respondents to the survey in the US.

Table 1. Location of study respondents and their ownership group.

\begin{tabular}{|c|c|c|c|}
\hline Region & Public Land Forest Planners $(n)$ & Private Land Forest Planners $(n)$ & Total $(n)$ \\
\hline South ${ }^{1}$ & 10 & 7 & 17 \\
\hline Midwest $^{2}$ & 4 & 1 & 5 \\
\hline Northeast ${ }^{3}$ & 5 & 7 & 12 \\
\hline West ${ }^{4}$ & 18 & 3 & 21 \\
\hline All & 37 & 18 & 55 \\
\hline
\end{tabular}

${ }^{1}$ Alabama, Arkansas, Florida, Georgia, Louisiana, Mississippi, North Carolina, Oklahoma, South Carolina, Tennessee, Texas, Virginia. ${ }^{2}$ Kentucky, Illinois, Indiana, Iowa, Michigan, Minnesota, Missouri, Ohio, Wisconsin. ${ }^{3}$ Connecticut, Delaware, Maine, Maryland, Massachusetts, New Hampshire, New Jersey, New York, Pennsylvania, Rhode Island, Vermont, West Virginia. ${ }^{4}$ Alaska, Arizona, California, Colorado, Hawaii, Idaho, Kansas, Montana, Nebraska, New Mexico, Nevada, North Dakota, Oregon, South Dakota, Utah, Washington, Wyoming.

In summary, about $67 \%$ of this forest and woodland area is covered by a management plan that was developed by publicly employed forest planners, and about $33 \%$ is covered by a management plan that was developed by privately employed forest planners.

On average, the respondents to our survey have been active in the forest management field for 17 years. Our analysis revealed that $51 \%$ of the public forest planner respondents have been involved in various stages of forest planning for more than ten years, compared with $83 \%$ of the private forest planner respondents. Table 2 illustrates the list of job titles for our respondents at their organization (adapted from the [78] job title classification). Results indicate the highest predominance of respondents identified themselves as foresters $(36.4 \%)$ and planners (23.6\%). Two issues we were unable to address in our questionnaire were the geographic reach of respondents' current forest planning efforts, and the variety of geographic situations in which they have participated in forest planning across the length of their careers. However, given the length of time the respondents, on average, have been involved in forest planning efforts, the broad geographic coverage of their current offices, and the diversity of 
organizations within which they work, we consider that the survey is fairly representative of the larger population and adequate for the purposes we stated in the introduction section of this manuscript.

Table 2. Job titles of survey respondents $(n=55)$.

\begin{tabular}{cccc}
\hline Job Title & \multicolumn{2}{c}{ Land Ownership Category } & \\
\hline Category & Public Lands & Private Lands & Percent \\
\hline Forester & 9 & 11 & 36.4 \\
Planner & 13 & 0 & 23.6 \\
Disciplinary specialist & 7 & 2 & 16.4 \\
Environmental coordinator & 2 & 0 & 3.6 \\
Others & 6 & 5 & 20.0 \\
Total & 37 & 18 & 100.0 \\
\hline
\end{tabular}

Most of our respondents completely answered all of the questions in the survey, though three people did not answer question 10, two people did not answer question 5 , three people did not answer question 7 , and two people did not answer question 8.

In the following sections, we describe: (1) what were the most frequent terms associated with sustainability and SFM, (2) in what manner do forest planners demonstrate forest sustainability within forest plans, and (3) to what extent does the conceptualization of sustainability in forest plans include considerations of environmental, social, and economic dimensions.

\subsection{Most Frequent Terms Associated with Sustainability and SFM}

Within the survey questionnaire, we specifically asked for a list of keywords that could be associated with sustainability and SFM. When asked to provide keywords (Figures 4 and 5), we found that acknowledgement of social values (e.g., thinking long-term, supporting society's needs) and stewardship (e.g., conserve, produce, ensure forest health) were the most frequently used to refer to sustainability and SFM.

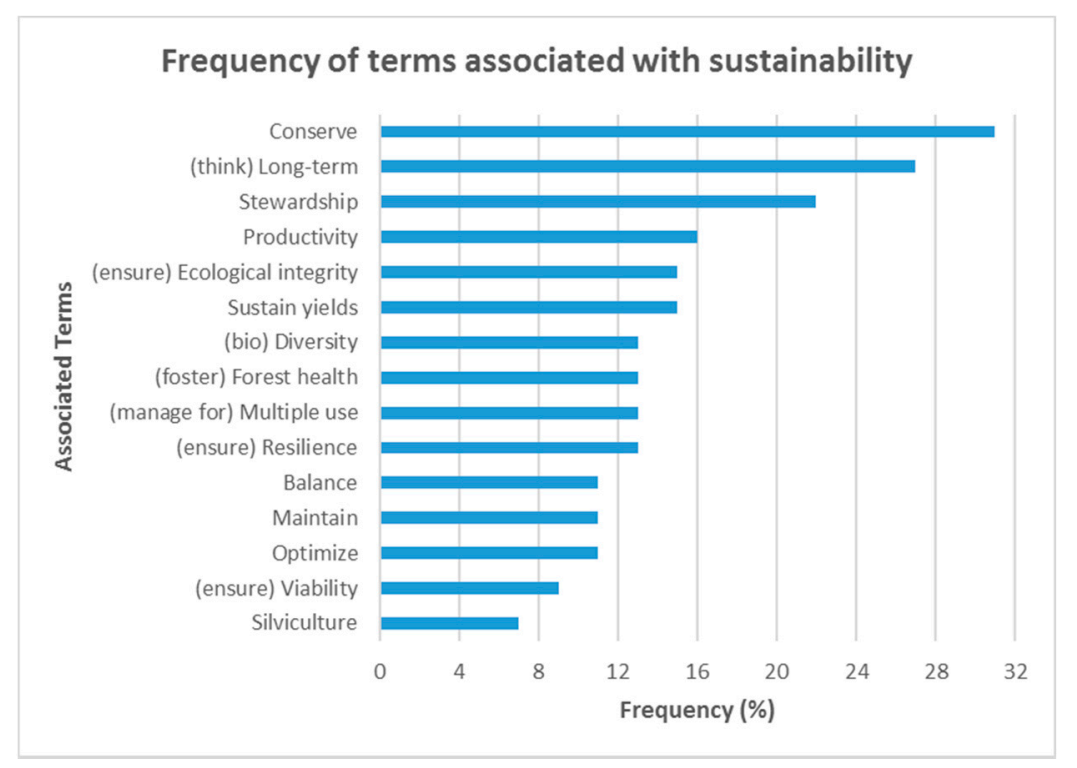

Figure 4. Frequency of terms associated with sustainability according to foresters and planners surveyed $(n=55)$. 


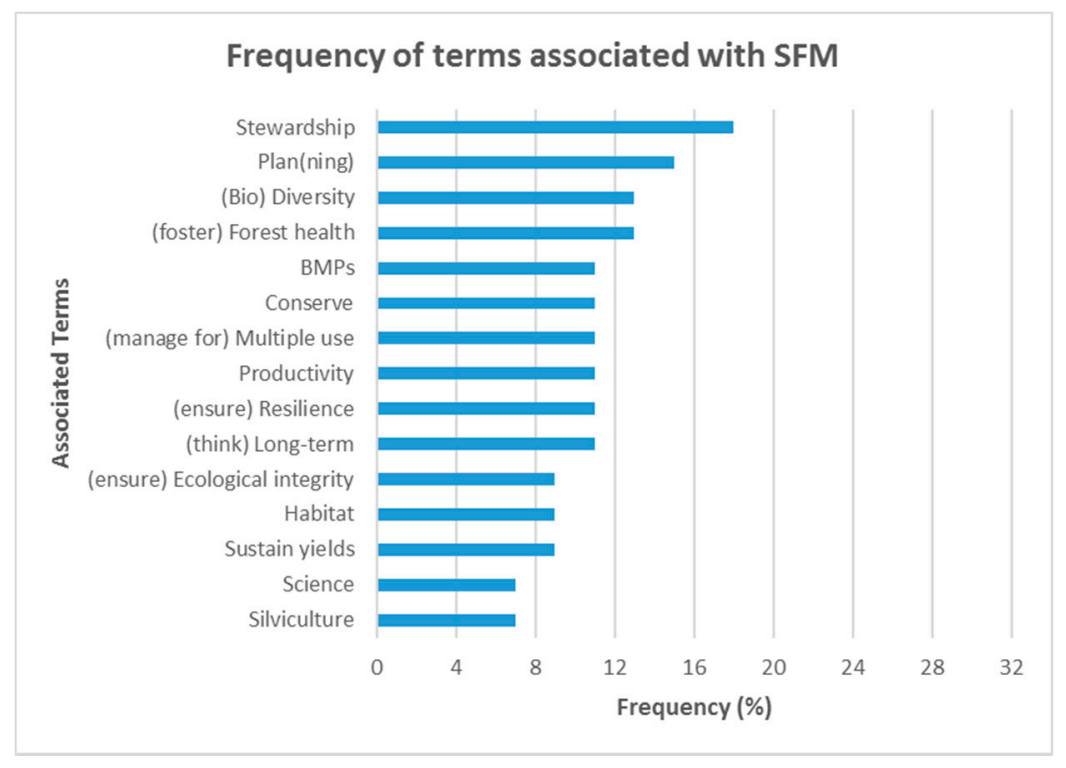

Figure 5. Frequency of terms associated with sustainable forest management (SFM) according to foresters and planners surveyed $(n=55)$.

The aggregated list of keywords that our respondents prioritized as to being related to sustainability and SFM were: (think) long-term, conserve, support, produce, (foster) forest health, (ensure) ecological integrity, sustain yields, (ensure) resilience, (ensure) viability, balance, plan, maintain, regenerate, perpetuate, and restore. In some cases, the use of these was similar for both sustainability and SFM (e.g., long-term was frequently noted) and in other cases dissimilar (e.g., maintain was less often noted in association with SFM and conserve was more often noted in association to both sustainability and SFM). Ecological integrity was also frequently associated with both sustainability and SFM. When asked for the order of importance of these terms, the study respondents often kept the order in which they mentioned at first. Figures 4 and 5 also reflect such order. For instance, long-term and productivity were put among the first and second in the list of terms associated with sustainability, whereas ecosystem health, sustain yields, and planning were often listed among the first and second terms associated with SFM. The keyword set provided by the respondents seemed to involve natural elements of the ecosystem rather than a holistic approach that would include social and economic components.

When asked to define sustainability, with medium to high frequency (Table 3), we found several of the same terms involving action (e.g., maintain, sustain and provide) and time frames (e.g., long-term and future) as we did from the list of keywords, perhaps indicating forward thinking on behalf of the planners and foresters. Among responses we received were also some vague definitions such as "sustainability equals conservation," "forestry that achieves sustainability," and "sustainability is an adverb that describes a condition, or action as sustainable, it is an awkward term." We also received some substantial definitions of sustainability, such as "the capacity of an ecosystem for long-term maintenance of ecological processes and functions, biological diversity, and productivity," "a system of management to allow current and future generations to enjoy and benefit from the many benefits of forests-timber, wildlife, water, and recreation," and "the capacity of forests to maintain their health, productivity, diversity, and overall integrity, in the long run, in the context of human activity and use." 
Table 3. Frequency of basic action terms associated with definitions of sustainability according to forest planners surveyed $(n=55)$.

\begin{tabular}{cc}
\hline Frequency & Basic Terms \\
\hline High (30-45) & think (long-term), maintain, (consider the) future, (be) capable or able \\
Medium (10-29) & (meet) needs, provide, sustain, perpetuate, use, (ensure) quality \\
Low (1-9) & $\begin{array}{c}\text { yield, protect, support, conserve, balance, (reach) capacity, regenerate, restore, } \\
\text { enhance, renew, repeat }\end{array}$ \\
\hline
\end{tabular}

Within these definitions are embedded several of the frequently used keywords noted above and in Figure 4, therefore underscoring their importance in understanding how forest planners think about forest sustainability. These terms can be grouped into families of related data types of which members are somehow related, while maintaining individual type identities and are able to be used interchangeably with respect to the family type. For example, with respect to our work, these families can be characterized as those that infer concrete action or philosophical principles, those that suggest an individual or a broader system are needed, those that refer to a temporal dimension, and those that suggest human versus technological views are necessary to achieve sustainability goals. With respect to principles versus concrete actions, conserve, produce, maintain, plan, balance, and manage for multiple uses would all seem to reflect concrete actions a forest manager might employ in their quest for a sustainable system, while ensuring forest health or integrity, being biodiverse, and ensuring resiliency would reflect broader principles a forest manager might follow. The latter group is often more vaguely defined, and processes to measure progress or success may currently be lacking. Individual forest landowners or managers can conserve, produce, maintain, plan, balance, optimize, and manage for multiple uses as can a collective or broader organization. These viewpoints are often shared amongst forest managers and landowners in North America, even though they may not act collectively to ensure that resources across broad landscapes are in fact managed in a sustainable manner. Further, actions to conserve, produce, maintain, plan, balance, optimize, and manage for multiple uses are likely unique human views of how one might manage sustainably a forest. From a technological point of view, actions to produce, maintain, plan, balance, and optimize a system may require data, technology, and knowledge beyond the scope of an individual. For some forested systems to be considered sustainable, a substantial commitment of time, energy, finances, and resources may be necessary. Inherently, many of the terms provided by the survey respondents infer a spatial dimension (the land that they manage or for which they develop a plan). However, the temporal dimension was directly mentioned once (think long-term) yet was implied in many other terms (conserve, maintain, plan, balance). These expression families help further organize the responses we received through our survey. Many responses refer to a concrete action expression family, as one might expect from practicing foresters and land managers. Similarly, many terms also fall into human expression family and the individual expression family. However, a portion of the respondents recognized that technology might play an important role in achieving a sustainable system, and that broader, vaguer ideals are still important for society to consider.

\subsection{Demonstration of Forest Sustainability within Forest Plans}

Respondents generally conveyed through their responses that the identification of forest-based objectives and goals was one way in which a commitment to sustainability is demonstrated in their forest plans. The objectives and goals are often linked to the desired conditions of a forest, to the compliance with relevant laws and regulations, and to the fulfillment of the standards and guidelines of forest certification programs. For example, in California landowners who desire to participate in the forest carbon program are required to develop a management plan with clear strategies and management activities to demonstrate, among others, the permanence (over a period of 100 years) of the forest carbon project. Requirements such as these suggest that forests managed to comply with these and other standards (e.g., forest certification) could be meeting a higher standard of forest 
sustainability that is verifiable. Objectives and goals also inform management prescriptions and guide management direction. A monitoring report and an assessment and implementation of forest modelling were also elements mentioned by forest planners as ways to demonstrate sustainability in the forest plans. An emphasis on specific "drivers," such as forest health, restoration, regeneration, control of invasive species, particularly when added to economic viability, collaborative partnerships, and silviculture practices, were identified as other ways to demonstrate a commitment to sustainability through forest plans.

More definitive responses for demonstrating sustainability in forest plans included "... through the articulation of its policy such as harvest volume flow control from decade to decade and the available merchantable inventory shown available through forest modeling" and "... specific tables demonstrating forest volumes recovery time, or maintained/increasing volumes, specific silviculture outlines for each property condition or stand." Explicit examples like these clearly indicate that a plan of action may lead to a sustainable system. In contrast, among responses to this portion of the survey were some ambiguous statements such as "our plans demonstrate commitment to sustainable forest management through maintaining our timber program's certification ... " and "the forest plan is the expression of sustainability by imposing constraints and goals." It appeared to be a consensus among respondents that the language employed in forest plans may not be sufficient to demonstrate sustainability of forests. What may truly be required (according to our respondents) are statements of measurable progress toward sustainability indicators and planned accomplishments. Our results also suggest that the use of language, and its ability to provide clarity on forest management and demonstrations of forest sustainability, has not been very deeply considered by some forest planners. For example, some respondents indicated that sustainability should be implied by the presence of a forest plan.

\subsection{Considerations of the Dimensions of Sustainability}

Four important considerations for forest sustainability were identified by our respondents-(1) ecological (environmental dimension); (2) production (economic dimension); (3) socio-cultural (social dimension); and (4) policy and legal frameworks (Table 4). The latter is understood as a functional element that connects the previous three. It is important to mention that the frequency of key statements in Table 4 is not necessarily associated with the weight given to each consideration. Instead, the statements indicate how often each consideration was communicated by our respondents in forest plans. Our study respondents emphasized most often a general "long-term production" of a forest ecosystem as a condition that determines a forest system to be sustainable. Similarly, general statements regarding "long-term management" and "long-term management for future generations" were also frequently offered and suggest that successful management over time can act as a condition that determines a forest system to be sustainable. We also found that meeting owners' objectives plays an important role as a condition of being sustainable, as well as compliance with laws, regulations, or standards associated with certification programs. We expected the responses to more specifically reflect one or more considerations of the three dimensions of sustainability (environment, society, and economy), but this was not the case.

With regard to the extent to which each of the considerations are employed when developing and implementing forest plans (according to our respondents), we determined that the conceptualization of sustainability in forest plans often includes considerations of environmental, social, and economic dimensions regardless of who owns the land. However, we noted that the environmental dimension prevailed over the social and economic considerations. Consideration for the environment was communicated through statements such as "stay true to ecology and biodiversity and don't let social or economic pressures dictate your actions," "... protect watersheds and manage for wildlife habitats," "conserve ecological function across the landscape ...," and "understand species interactions and their performance in different sites and soil type." Economic and policy considerations were communicated by some respondents through statements such as "achieve economic profitability while maintaining 
or improving land for wildlife, wood production, soil and water conservation," "use certification guidelines," and "use of best available science."

Table 4. Main considerations for forest sustainability according to respondents.

\begin{tabular}{cc}
\hline Principles & Key Statements \\
\hline Ecological & Maintain forest biodiversity \\
& Maintain soil and site productivity \\
Maintain health and vitality of forest \\
Provide for forest regeneration
\end{tabular}

\section{Discussion}

In the near future, we intend to conduct an extensive content analysis, involving several hundred current forest plans that we have collected from public and private organizations in the United States. The purpose of the pending content analysis is to determine how the path to forest sustainability is explicitly demonstrated in forest plans. Certainly, we could have pursued this endeavor using a keyword set that we developed internally, yet we decided to inform this future work with the survey of forest planners that was presented here. We learned from this survey that, in spite of decades of scholarly and practical development of forest sustainability definitions, principles, and concepts, multiple potentially incommensurable definitions of sustainability and SFM are understood and operationalized by forest planners. Each definition provided by our study respondents had a distinct focus, and each had the potential to be applied in diverse contexts. The diversity in responses to the definitions of sustainability and SFM prompt us to reject our first hypothesis, that forest planners are guided by a consistent concept of forest sustainability. For various reasons we mentioned, including their employment situation, we observed a considerable amount of variation in survey responses by our sample set of respondents. Sustainability, when defined, is often broad and vague, and therefore open to diverse and conflicting interpretation [9].

European thoughts on forest management are integrated into North American educational and professional systems, as in general it is held that the purpose of forestry is to secure permanent benefits to human society and nature [79]. The terms we obtained to describe sustainability can arguably be interrelated and used similarly by different people depending on their educational and social backgrounds. For example, to "conserve" a resource can suggest to "preserve" a resource [80]. Within the context of forestry educational and professional systems, a sustainable forest ecosystem is often described as being productive, natural, and diverse. Interestingly, the terms productive, stable, sustainable, and equitable are sometimes considered separate properties of managed systems that might conflict, depending on the management circumstance [81]. However, it has long been considered 
in forest management that sustained yields of wood products can equate to constant production [82]. Many of the terms we derived from survey respondents therefore suggest that a sustainable forest system involves the management of nature, and a possible sacrifice by current generations of society for future generations.

Our second hypothesis (that environmental, social, and economic dimensions are thoroughly addressed in forest plans) was somewhat supported given the responses provided by forest planners. An acknowledgement of each dimension was observed, yet the depth to which they were addressed in the responses we obtained varied, perhaps due to the diversity of objectives and goals important to the people or organizations that own the land. Further, these three dimensions of sustainability were accounted for in an uneven and partial manner. Even though all respondents to our survey recognized the importance of the three dimensions of sustainability, our results revealed a greater emphasis on the environmental considerations than on the social and economic considerations. Arguably, the social component of sustainability may be the most difficult to address, but the economic component may have the best potential to be demonstrated explicitly through, for example, well-known quantitative assessments of yields, costs, and prices. Perhaps, forest planners and the interdisciplinary teams developing forest plans can describe more thoroughly how demonstrations of forest sustainability (e.g., volume flow control, volume yields, and modeling) or even the implications of the management alternatives and activities that reflect sustainable solutions, affect communities and the environment. Perhaps, linking technical aspects such as these to specific impacts on local communities could not only improve the understanding of the decisions made by public and private forest organizations, but also the social acceptance and support for their implementation. An increase in the use of language reflecting the concrete actions an organization might pursue with respect to social and economic outcomes of a sustainable plan considerations may be necessary, rather than language that addresses broader principles. However, as we noted, a substantial commitment of time, energy, finances, and resources may be necessary. For private lands forest planners, many seemed to recognize the importance of public participation in the decision process, yet the social dimension was emphasized to a lesser extent in their responses likely because public participation is not required in the private land forest planning process in the United States. For public land forest planners who are employed by the federal government, it may still be difficult to determine whether statements that address sustainability correspond to the most recent representation of sustainability adopted (that emphasizes the interdependences between environment, society, and economy) or a previous conceptualization (represented by intersected dimensions of sustainability, but not fully integrated into the forest system) [83].

There are important limitations to this study. It needs to be understood that this study was part of a broader project that aims to conduct a content analysis of forest plans in the United States to understand how sustainability and SFM are communicated and demonstrated through these plans. We recognize that it is possible that longer, in-depth interviews would have provided much more detailed information about the terms foresters and planners use to infer sustainability within forest management plans. However, there are also benefits in consistency, replicability, and the advantage of providing greater depth than a closed-ended survey [84]. Certainly, future studies should take into consideration their particular interests as the specific constraints for choosing to deliver a survey via email or via phone (as described by for example [69,70]). In addition, more in-depth interviews could allow for the collection of richer qualitative data. In addition, the level of preparation each respondent underwent to address each question was unknown. We believe that their answers reflect their beliefs and the manner in which they develop forest plans. We understand that it is possible certain terms which could be used to demonstrate sustainability were not mentioned by our respondents even though they may appear in the forest plans. An example of this could be the terms "restoration" and "resilience" infrequently mentioned by our respondents, though one might expect to be included on a list of terms referred to sustainability and SFM. While most of the terms we obtained from survey respondents focused on stability (standing, enduring, maintaining original condition) the ability of a system to be resilient (to absorb changes and persist) was not one of these. Resilience suggests that the 
management system would take a broader view and keep options open [85]. It has been suggested that to cope effectively with change, a resilient system would be more advantageous than a stable system [9]. Pending research will be able to better understand the use of terms such as these in forest plans.

Finally, statements regarding the projected management prescriptions, the estimated management direction, and descriptions of the current and future conditions could contain explicit demonstrations of sustainable environment, social, and economic dimensions of a forest. However, these were not well described through our survey, perhaps due to the manner in which the open-ended questions were presented. Ultimately, the desired outcome of concerns about the sustainability of a system involves the maintenance of human and ecosystem health needs [9]. Human needs are both tangible and intangible, and they contribute to society's health and well-being [9]. Although we acknowledge that sustainable forestry plays a fundamental role in maximizing the amount of carbon stored over time and that by maintaining forest processes, forest managers can help forest ecosystems resist natural events associated with climate change, the association was not explicitly made by our study respondents. Certainly, the objectives and goals of the landowner for which a plan is developed, guide what is to be sustained within a forest. Yet, contributing to carbon sequestration and reacting climate change were not high on the list of objectives and goals, perhaps due to the immediacy of a forest planning effort (a limited time horizon). These limitations notwithstanding, we found our survey to be a useful tool for identifying the list of key terms that foresters and planners frequently associate with forest sustainability and SFM and the potentially explicit ways by which these professionals think sustainability of forests is demonstrated through forest plans.

\section{Conclusions}

In the last century, the overarching goal of forestry has been to manage sustainable forest ecosystems. Yet, time, social values, and perspectives on the environment have changed. Simply saying forest management is sustainable without demonstrating this through analysis may not suffice. Real, positive impacts on forest ecosystems and social well-being may not be evident until a consistent use of language and terms associated with sustainability and SFM is employed. We based our need for this project in the lack of clarity and explicit or empirical evidence of forest sustainability that previous studies suggested (e.g., [20,46,47]). We found that while forest planners may have a clear knowledge base to address forest considerations thoroughly, when asked to communicate it, some struggle. A few respondents of our survey recognized that an improvement in the language in forest plans might help demonstrate forest sustainability since they heavily rely on terminology that is employed in their daily routines, policies, and forest certification guidelines. Some respondents also felt that the discourse contained in a forest plan should be valid and sufficient to demonstrate a commitment to sustainability. Our results should benefit both public agencies and the private sector by providing unique information on how language is being used to communicate and demonstrate sustainability. Our hope is that forest landowners will acknowledge the need to maintain a continuous dialogue among diverse stakeholders to facilitate understanding and clarification about concepts and interpretations for sustainability and SFM. Ideally, a consensus among actors should reveal a more comprehensive way to demonstrate a commitment to sustainability in their forest management documents and to communicate outcomes that reflect progress towards sustainability goals. As the general public becomes more aware and informed about environmental issues and their influence in the socio-economic characteristics of local and national livelihoods, we expect that forest planners and policy makers may consider the results of this study as an evidence of the active need to improve the communication of sustainability in forest plans. Recognizing that sometimes interdisciplinary teams work on the development and implementation of forest plans, and that the structure of these teams is of particular importance to ensure an integrated participation of subject-matter experts to address particular environmental issues [76], we suggest that future studies consider a deeper analysis of the education and experiential background of the study respondents to assess the potential effect of such efforts for influencing and changing the discourse around forest sustainability. The quality and depth 
of training on forest sustainability, and the uptake of concepts by planners, may be difficult to measure, yet may be influential in their ability and willingness to expand the language contained in a forest plan. These considerations could also help to better understand how and why each group of people, based on their associated demographics, differ in how they address and demonstrate sustainability in forest plans.

Author Contributions: All authors were involved in designing this research. The first author carried out the surveys and performed the analysis. All other authors provided advice, comments and substantive input to the writing of the manuscript. All authors have read and agreed to the published version of the manuscript.

Funding: This research was funded by USDA NIFA grant 2015-10780.

Conflicts of Interest: The authors do not have any conflicts of interest to declare.

\section{References}

1. Wiersum, K.F. 200 years of sustainability in forestry: Lessons from history. Environ. Manag. 1995, 19, 321-329. [CrossRef]

2. Vehkamäki, S. The concept of sustainability in modern times. In Sustainable Use of Renewable Resources_From Principles to Practices; Jalkanen, A., Nygren, P., Eds.; University of Helsinki Department Ecology: Helsinki, Finland, 2005; pp. 25-35.

3. Spindler, E.A. The history of sustainability: The origins and effects of a popular concept. In Sustainability in Tourism: A Multidisciplinary Approach; Jenkins, I., Schröder, R., Eds.; Springer: Wiesbaden, Germany, 2013; pp. 9-31.

4. Nieuwenhuis, M. Terminology of Forest Management, Terms and Definitions in English, 2nd ed.; IUFRO World Series Volume 9-en; International Union of Forest Research Organizations: Vienna, Austria, 2010; p. 176.

5. Helms, J.A. (Ed.) The dictionary of Forestry; Society of American Foresters: Bethesda, MD, USA, 1998.

6. Food and Agriculture Organization of the United Nations. What Is Sustainable Forest Management (SFM)? Food and Agriculture Organization of the United Nations: Rome, Italy, 2018. Available online: http: //www.fao.org/forestry/sfm/85084/en/ (accessed on 15 March 2019).

7. Programme for the Endorsement of Forest Certification. What Is Sustainable Forest Management? Programme for the Endorsement of Forest Certification: Geneva, Switzerland, 2019. Available online: https://www.pefc. org/what-we-do/our-approach/what-is-sustainable-forest-management (accessed on 5 May 2019).

8. Rainforest Alliance. What Is Sustainable Forestry? Rainforest Alliance: New York, NY, USA, 2019. Available online: https://www.rainforest-alliance.org/articles/what-is-sustainable-forestry (accessed on 15 March 2019).

9. Dovers, S.R.; Handmer, J.W. Uncertainty, sustainability and change. Glob. Environ. Chang. 1992, 2, 262-276. [CrossRef]

10. Fisher, J.; Rucki, K. Re-conceptualizing the science of sustainability: A dynamical systems approach to understanding the nexus of conflict, development and the environment. Sustain. Dev. 2017, 25, 267-275. [CrossRef]

11. Lubin, D.A.; Esty, D.C. The sustainability imperative. Harv. Bus. Rev. 2010, 88, 8 .

12. Vollero, A.; Siano, A.; Della Volpe, M. A systems perspective for conceptualizing sustainability in long-lived family businesses. Research proposals on risk taking and innovativeness. Syst. Res. 2019, 36, 111-127. [CrossRef]

13. Chesson, M.S.; Ullah, I.I.; Ames, N.; Benchekroun, S.; Forbes, H.; Garcia, Y.; Iiriti, G.; Lazrus, P.K.; Robb, J.; Squillaci, M.O. Laborscapes and archaeologies of sustainability: Early globalization and commercial farming in the San Pasquale Valley, Calabria, Italy from AD 1800-2018. J. Mediterr. Archaeol. 2019, 32, 32-62. [CrossRef]

14. Staniškienè, E.; Stankevičiūtè, Ž. Social sustainability measurement framework: The case of employee perspective in a CSR-committed organisation. J. Clean. Prod. 2018, 188, 708-719. [CrossRef]

15. Šimunović, N.; Stern, T.; Hesser, F. Is sustainable forest management enough? Insights from a frame analysis of European environmental non-governmental organizations. Austrian J. For. Sci. 2019, 136, 87-140.

16. World Commission on Environment and Development. Report of the World Commission on Environment and Development: Our common Future; World Commission on Environment and Development: Oxford, UK, 1987. 
17. Ahimin, A.O.; Mikissa, J.B.; Johnson, S.; N'Guessan Kouamé, F.; Kamanzi, K. Implementing principles, criteria and indicators for sustainable forest management in Gabon. J. Sustain. For. 2019, 38, 46-53. [CrossRef]

18. Lombardo, E.; Maetzke, F. Evaluation, analysis and perception of sustainable forest management through the lens of the PEFC forest certification using two case studies in Sicily. Int. For. Rev. 2019, 21, 73-91. [CrossRef]

19. Pearce, D.; Putz, F.E.; Vanclay, J.K. Sustainable forestry in the tropics: Panacea or folly? For. Ecol. Manag. 2003, 172, 229-247. [CrossRef]

20. Siry, J.P.; Cubbage, F.W.; Ahmed, M.R. Sustainable forest management: Global trends and opportunities. For. Policy Econ. 2005, 7, 551-561. [CrossRef]

21. Baumgartner, R.J. Sustainable development goals and the forest sector-A complex relationship. Forests 2019, 10, 152. [CrossRef]

22. Lazdinis, M.; Angelstam, P.; Pülzl, H. Towards sustainable forest management in the European Union through polycentric forest governance and an integrated landscape approach. Landsc. Ecol. 2019, 34, 1737-1749. [CrossRef]

23. Rametsteiner, E.; Simula, M. Forest certification-An instrument to promote sustainable forest management? J. Environ. Manag. 2003, 67, 87-98. [CrossRef]

24. Bettinger, P.; Boston, K.; Siry, J.P.; Grebner, D.L. Forest Management and Planning, 2nd ed.; Academic Press: New York, NY, USA, 2017.

25. Sample, V.A. Sustainability in Forestry: Origins, Evolution and Prospects; Pinchot Institute for Conservation: Washington, DC, USA, 2004.

26. Sedjo, R.A.; MacCleery, D. Sustainable forests in America? In Perspectives on Sustainable Resources in America; Sedjo, R.A., Ed.; Routledge: Washington, DC, USA, 2010; pp. 32-73.

27. Salas-Garita, C.; Jones-Román, G. Manejo forestal sostenible del bosque y monitoreo ecológico en dos bosques muy húmedos tropicales de Zona Norte de Costa Rica. Rev. For. Mesoam. Kurú 2019, 16, 10-22. [CrossRef]

28. Intergovernmental Panel on Climate Change. IPCC Special Report on Climate Change, Desertification, Land Degradation, Sustainable Land Management, Food Security, and Greenhouse Gas Fluxes in Terrestrial Ecosystems. Summary for Policymakers; IPCC Secretariat: Geneva, Switzerland, 2019.

29. Barnes, M.; Delaney, M. Management Plan Guidance Supplement for Carbon Sequestration; American Forest Foundation: Washington, DC, USA, 2010.

30. Yakama Nation and the Bureau of Indian Affairs. Forest Management Plan, Yakama Reservation; U.S. Department of the Interior, Bureau of Indian Affairs, Yakama Agency Branch of Forestry, and the Yakama Nation: Toppenish, WA, USA, 2005; p. 259.

31. U.S. Forest Service. Tongass Land and Resource Management Plan, Final Environmental Impact Statement, Plan Amendment, Record of Decision; U.S. Department of Agriculture, Forest Service, Alaska Region: Juneau, AK, USA, 2008; R10-MB-603a.

32. U.S. National Park Service. Blue Ridge Parkway, Virginia and North Carolina, Final General Management Plan/Environmental Impact Statement; U.S. Department of the Interior, National Park Service, Denver Service Center: Denver, CO, USA, 2013.

33. Richardson, R. Management recommendations, Denise Poole and Lisa Pianta; Appalachian Investments: Arnoldsburg, WV, USA, 2013; p. 22.

34. The Nature Conservancy and Albany Department of Water \& Water Supply. Albany Water Forestland: Working Woodlands Forest Management Plan; The Nature Conservancy, New York Program, Highland, NY and Albany Department of Water \& Water Supply: Albany, NY, USA, 2018.

35. Wayburn, L.A.; Franklin, J.F.; Gordon, J.C.; Binkley, C.S.; Mladenoff, D.J.; Christensen, N.L.C., Jr. Forest Carbon in the United States: Opportunities and Options for Private Lands; Pacific Forest Trust, Inc.: San Francisco, CA, USA, 2000.

36. U.S. Forest Service. Baseline Estimates of Carbon Stocks in Forests and Harvested Wood Products for National Forest System Units; U.S. Department of Agriculture, Forest Service, Rocky Mountain Region, Climate Change Advisor's Office: Lakewood, CO, USA, 2015.

37. Dong, L.; Bettinger, P.; Liu, Z.; Qin, H. Spatial forest harvest scheduling for areas involving carbon and timber management goals. Forests 2015, 6, 1362-1379. [CrossRef]

38. Stwertka, C.; Parshley, L. Carbon Sequestration in the Chequamegon-Nicolet National Forest; Environmental Law \& Policy Center: Chicago, IL, USA, 2009. 
39. Shultz, J.; Durkay, J. State Forest Carbon Incentives and Policies; National Conference of State Legislatures: Washington, DC, USA, 2018.

40. Baun, M. ARCATA FWO: Landmark Van Eck Forest Safe Harbor Agreement to Benefit Northern Spotted Owls; U.S. Fish and Wildlife Service FieldNotes, Region 8: Sacramento, CA, USA, 2009.

41. Reeves, T.; Mei, B.; Bettinger, P.; Siry, J. Review of the effects of conservation easements on surrounding property values. J. For. 2018, 116, 555-562. [CrossRef]

42. Forest Climate Action Team. California Forest Carbon Plan: Managing our Forest Landscapes in a Changing Climate; Forest Climate Action Team: Sacramento, CA, USA, 2018.

43. Angelstam, P.; Elbakidze, M.; Axelsson, R.; Khoroshev, A.; Pedroli, B.; Tysiachniouk, M.; Zabubenin, E. Model forests in Russia as landscape approach: Demonstration projects or initiatives for learning towards sustainable forest management? For. Policy Econ. 2019, 101, 96-110. [CrossRef]

44. Bettinger, P. Distributing GIS capabilities to forestry field offices: Benefits and challenges. J. For. 1999, 97, 22-26. [CrossRef]

45. Food and Agriculture Organization of the United Nations. Global Forest Resources Assessment 2015. How Are the World's Forests Changing? 2nd ed.; Food and Agriculture Organization of the United Nations: Rome, Italy, 2015.

46. Brandt, J.S.; Nolte, C.; Steinberg, J.; Agrawal, A. Foreign capital, forest change and regulatory compliance in Congo Basin forests. Environ. Res. Lett. 2014, 9, 044007. [CrossRef]

47. Koontz, T. Differences between state and federal public forest management: The importance of rules. Publius J. Fed. 1997, 27, 15-38. [CrossRef]

48. Singh, S.; Holvoet, N.; Pandey, V. Bridging sustainability and corporate social responsibility: Culture of monitoring and evaluation of CSR initiatives in India. Sustainability 2018, 10, 2353. [CrossRef]

49. Hargrove, E. Toward teaching environmental ethics: Exploring problems in the language of evolving social values. Can. J. Environ. Educ. 2000, 5, 114-133.

50. Marshall, J.D.; Toffel, M.W. Framing the elusive concept of sustainability: A sustainability hierarchy. Environ. Sci. Technol. 2005, 39, 673-682. [CrossRef] [PubMed]

51. Primmer, E.; Karppinen, H. Professional judgment in non-industrial private forestry: Forester attitudes and social norms influencing biodiversity conservation. For. Policy Econ. 2010, 12, 136-146. [CrossRef]

52. Weller, S.C.; Vickers, B.; Bernard, H.R.; Blackburn, A.M.; Borgatti, S.; Gravlee, C.C.; Johnson, J.C. Open-ended interview questions and saturation. PLoS ONE 2018, 13, e0198606. [CrossRef]

53. Goodman, L.A. Snowball sampling. Ann. Math. Stat. 1961, 32, 148-170. [CrossRef]

54. Magnani, R.; Sabin, K.; Saidel, T.; Heckathorn, D. Review of sampling hard-to-reach and hidden populations for HIV surveillance. Aids 2005, 19, S67-S72. [CrossRef]

55. Tansey, O. Process tracing and elite interviewing: A case for non-probability sampling. PS: Polit. Sci. Polit. 2007, 40, 765-772. [CrossRef]

56. Noy, C. Sampling knowledge: The hermeneutics of snowball sampling in qualitative research. Int. J. Soc. Res. Methodol. 2008, 11, 327-344. [CrossRef]

57. Damschroder, L.J.; Aron, D.C.; Keith, R.E.; Kirsh, S.R.; Alexander, J.A.; Lowery, J.C. Fostering implementation of health services research findings into practice: A consolidated framework for advancing implementation science. Implement. Sci. 2009, 4, 50. [CrossRef] [PubMed]

58. Tabak, R.G.; Khoong, E.C.; Chambers, D.A.; Brownson, R.C. Bridging research and practice: Models for dissemination and implementation research. Am. J. Prev. Med. 2012, 43, 337-350. [CrossRef] [PubMed]

59. Biernacki, P.; Waldorf, D. Snowball sampling: Problems and techniques of chain referral sampling. Sociol. Methods Res. 1981, 10, 141-163. [CrossRef]

60. Goel, S.; Salganik, M.J. Assessing respondent-driven sampling. Proc. Natl. Acad. Sci. USA 2010, 107, 6743-6747. [CrossRef]

61. Faugier, J.; Sargeant, M. Sampling hard to reach populations. J. Adv. Nurs. 1997, 26, 790-797. [CrossRef]

62. Baltar, F.; Brunet, I. Social research 2.0: Virtual snowball sampling method using Facebook. Internet Res. 2012, 22, 57-74. [CrossRef]

63. McBride, M.F.; Duveneck, M.J.; Lambert, K.F.; Theoharides, K.A.; Thompson, J.R. Perspectives of resource management professionals on the future of New England's landscape: Challenges, barriers, and opportunities. Landsc. Urban. Plan. 2019, 188, 30-42. [CrossRef] 
64. Tourangeau, R.; Couper, M.P.; Conrad, F. Spacing, position, and order: Interpretive heuristics for visual features of survey questions. Public Opin. Q. 2004, 68, 368-393. [CrossRef]

65. Dillman, D.A.; Smyth, J.D.; Christian, L.M. Internet, Phone, Mail, and Mixed-Mode Surveys, 4th ed.; John Wiley \& Sons: Hoboken, NJ, USA, 2014.

66. DiCicco-Bloom, B.; Crabtree, B.F. The qualitative research interview. Med. Educ. 2006, 40, 314-321. [CrossRef]

67. Bolderston, A. Conducting a research interview. J. Med. Imaging Radiat. Sci. 2012, 43, 66-76. [CrossRef] [PubMed]

68. Bartholomew, K.; Henderson, A.J.Z.; Marcia, J.E. Coded semistructured interviews in social psychological research. In Handbook of Research Methods in Social and Personality Psychology; Reis, H.T., Judd, C.M., Eds.; Cambridge University Press: Cambridge, UK, 2000; pp. 286-312.

69. Bowling, A. Mode of questionnaire administration can have serious effects on data quality. J. Public Health 2005, 27, 281-291. [CrossRef] [PubMed]

70. Stephens, N. Collecting data from elites and ultra elites: Telephone and face-to-face interviews with macroeconomists. Qual. Res. J. 2007, 7, 203-216. [CrossRef]

71. Krippendorff, K. Content Analysis: An. Introduction to its Methodology, 4th ed.; SAGE Publications, Inc.: Los Angeles, CA, USA, 2019.

72. Burnard, P. A method of analysing interview transcripts in qualitative research. Nurse Educ. Today 1991, 11, 461-466. [CrossRef]

73. Strauss, A.; Corbin, J. Basics of Qualitative Research, 3rd ed.; SAGE Publications, Inc.: Los Angeles, CA, USA, 1998.

74. Goldhaber-Fiebert, S.N.; Pollock, J.; Howard, S.K.; Merrell, S.B. Emergency manual uses during actual critical events and changes in safety culture from the perspective of anesthesia residents: A pilot study. Anesth. Analg. 2016, 123, 641-649. [CrossRef]

75. Baron, N.S.; Calixte, R.M.; Havewala, M. The persistence of print among university students: An exploratory study. Telemat. Inform. 2017, 34, 590-604. [CrossRef]

76. Oswalt, S.N.; Smith, W.B.; Miles, P.D.; Pugh, S.A. Forest Resources of the United States, 2017; Gen. Tech. Rep. WO-97; U.S. Department of Agriculture, Forest Service: Washington, DC, USA, 2019. [CrossRef]

77. Butler, B.J.; Hewes, J.H.; Dickinson, B.J.; Andrejczyk, K.; Butler, S.M.; Markowski-Lindsay, M. USDA Forest Service National Woodland Owner Survey: National, Regional, and State Statistics for Family Forest and Woodland Ownerships with 10+ Acres, 2011-2013; Res. Bull. NRS-99; U.S. Department of Agriculture, Forest Service, Northern Research Station: Newtown Square, PA, USA, 2016.

78. Cerveny, L.K.; Blahna, D.J.; Stern, M.J.; Mortimer, M.J.; Freeman, J.W. Forest Service interdisciplinary teams: Size, composition, and leader characteristics. J. For. 2011, 109, 201-207. [CrossRef]

79. Anić, I.; Meštrović, Š.; Matić, S. Značajniji događaji iz povijesti šumarstva u hrvatskoj (Important events in the history of forestry in Croatia). Šumar. List 2012, 136, 169-177.

80. Ely, R.T. Conservation and economic theory. Trans. Am. Inst. Mining Eng. 1917, 54, 458-473.

81. Conway, G.R. The properties of agroecosystems. Agric. Syst. 1987, 24, 95-117. [CrossRef]

82. Higgs, L.S. Rotation of cutting to secure a sustained yield from the Crown timber lands of British Columbia. J. For. 1911, 9, 568-573.

83. U.S. Department of Agriculture, Natural Resources Conservation Service. A Guide for Foresters and other Natural Resource Professionals on Using: MANAGING your Woodlands: A Template for Your Plans for the Future; Department of Agriculture, Natural Resources Conservation Service: Washington, DC, USA, 2011.

84. Janse, G.; Konijnendijk, C.C. Communication between science, policy and citizens in public participation in urban forestry-Experiences from the Neighbourwoods project. Urban. For. Urban. Green. 2007, 6, $23-40$. [CrossRef]

85. Holling, C.S. Resilience and stability of ecological systems. Annu. Rev. Ecol. Syst. 1973, 4, 1-23. [CrossRef] 